\title{
SILYBIN AND SILYMARIN - NEW EFFECTS AND APPLICATIONS
}

\author{
Vladimír Křen a,b, Daniela Walterováb \\ ${ }^{a}$ Institute of Microbiology, Academy of Sciences of the Czech Republic, Videňská 1083, CZ-142 20 Prague, Czech \\ Republic \\ ${ }^{b}$ Institute of Medical Chemistry and Biochemistry, Faculty of Medicine, Palacký University, Hněvotínská 3, CZ-775 15 \\ Olomouc, Czech Republic
}

Received: June 2, 2005; Accepted (with revisions): June 24, 2005

Key words: Silymarin/Silybin/Anticancer activity/P-glycoprotein/Receptors

This article aims to review critically literature published mainly within this millennium on the new and emerging applications of silymarin, the polyphenolic fraction from the seeds of Silybum marianum and its main component silybin. Silymarin and silybin used so far mostly as hepatoprotectants were shown to have other interesting activities as e.g., anticancer and canceroprotective. These activities were demonstrated in a large variety of illnesses of different organs as e.g., prostate, lungs, CNS, kidneys, pancreas and others. Besides the cytoprotective activity of silybin mediated by its antioxidative and radical-scavenging properties also new activities based on the specific receptor interaction were discovered - e.g., inhibition and modulation of drug transporters, P-glycoproteins, estrogenic receptors, nuclear receptors and some others. New derivatives of silybin open new ways to its therapeutic applications. Pharmacology dealing with optically pure silybin diastereomers may suggest new mechanisms of its action.

\section{INTRODUCTION}

Seeds of Silybum marianum (L.) Gaertn. (Carduus marianus L., Asteraceae) (milk thistle) have been used for more than 2000 years to treat liver and gallbladder disorders, including hepatitis, cirrhosis, and jaundice, and to protect the liver against poisoning from chemical and environmental toxins, including snake bites, insect stings, mushroom poisoning, and alcohol. This medicinal plant has been used from ancient times - Theoprastus $\left(4^{\text {th }}\right.$ century B. C.) was probably the first one who described it under the name "Pternix", and later it was mentioned by Dioskurides in his "Materia medica" $\left(1^{\text {st }}\right.$ century A. D.) and by Plinius ( $1^{\text {st }}$ century A. D.). Although numerous medicinal pieces of knowledge were forgotten in the Dark Ages and later reinvented, the use of milk thistle has been systematically mentioned in all important medicinal herbaria e.g., by abbess Hildegarda von Bingen (1098-1179), Hyeronymus Bock (1593), Jacobus Theodorus (1664), Mattioli (1626), Valentini (1719), Von Haller (1755) and many others until the present time 1 .

Active component of this plant is silymarin ${ }^{1}$ - a standardized extract obtained from the seeds of $S$. marianum containing approximately $70 \%$ to $80 \%$ of the silymarin flavonolignans and approximately $20 \%$ to $30 \%$ chemically undefined fraction, comprising mostly polymeric and oxidized polyphenolic compounds. The main component of the silymarin complex is silybin (CAS No. 22888-70-6), synonymous with silibinin, sometimes incorrectly called silybinin. Besides silybin, which is a mixture of two diastereomers A and B in approximately $1: 1$ proportion (Fig. 1), considerable amounts of other flavonolignans are present in the silymarin complex, namely isosilybin, dehydrosilybin, silychristin, silydianin, and a few flavonoids, mainly taxifolin (Fig. 2)( ref. $^{2}$ ). White-flowering varieties of $S$. marianum contain ${ }^{3}$ in addition 3-deoxyflavanolign-

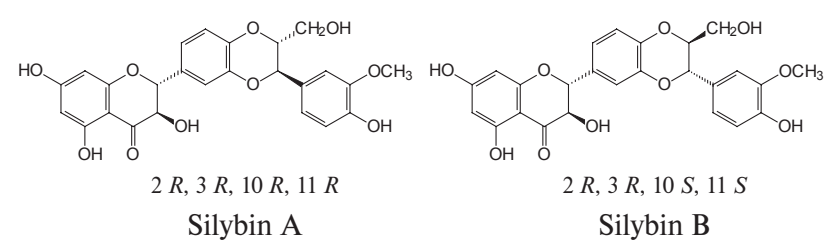

Fig. 1

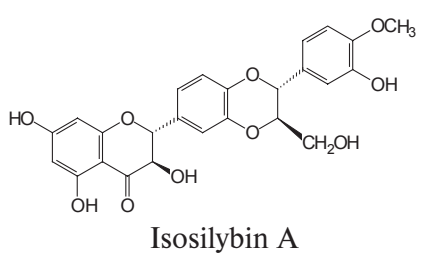

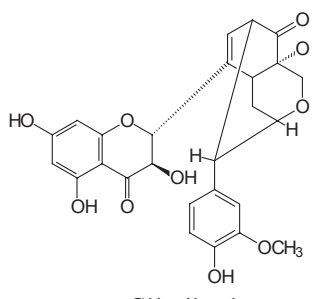<smiles>COc1cc(C2Oc3c(O)cc([C@@H]4Oc5cc(O)cc(O)c5C(=O)C4O)cc3[C@@H]2CO)ccc1O</smiles>

Silychristin<smiles>O=C1c2c(O)cc(O)cc2OC(c2ccc(O)c(O)c2)C1O</smiles>

(+)-Taxifolin
Fig. 2 
ans silandrin, silymonin, silyhermin and neosilyhermin $\mathrm{A}$ and $\mathrm{B}$.

Typical applications, for which milk thistle preparations have been used and prescribed since ancient times, are mostly treatments of liver diseases and GIT problems ${ }^{4,5}$. Also currently, silymarin/silybin and their preparations are advocated for the treatment of cirrhosis, chronic hepatitis and liver diseases associated with alcohol consumption and environmental toxin exposure ${ }^{6,7,125}$.

Pharmacological, medicinal and phytochemical literature discusses many polemics on the effects of silymarin and/or silybin. Some studies with silymarin and silybin are sometimes considered being controversial and they become a subject of numerous re-assessments ${ }^{8-10}$. The effectiveness of milk thistle in human liver disease has not been firmly established. This may be because of the scientific quality of study methods or published reports or both. Most frequently, but not consistently, possible benefits have been shown for the improvement in liver function tests (mainly serum alanine aminotransferase). Survival and other clinical measures have been reported rather rarely, with both positive and negative findings. Mechanisms of action, disease populations likely to benefit, optimal formulations of milk thistle, and duration of therapy are undefined.

The main reason for controversy and uncertainty of effects is the variable composition of silymarin preparations used in most of the studies. It has been well documented that the proportions of respective components in various silymarins depend largely on the source of S. marianum seeds (plant cultivar and cultivation conditions) and also on the extraction and processing procedures. Many studies often suffer from inconsistencies due to the use of non-standard silymarin (extract) and silybin (pure compound) preparations, and even confuse these terms in literature ${ }^{2}$.

Silymarin/silybin is considered to be very safe and there are only few reports on the adverse effects. Jacobs et al. ${ }^{10}$ reported in his meta-analysis only three serious adverse effects. A combination of herbal formula containing milk thistle induced at one patient gastroenteritis symptoms associated with "collapse" causing recurrent symptoms after the patient was rechallenged ${ }^{11}$. The other two described anaphylactic reactions after ingestion of Silybum marianum tea ${ }^{12,13}$. Gastrointestinal symptoms were the most common adverse effects reported. Overall, the frequency was low, ranging from $2 \%$ to $10 \%$ in controlled trials, which was indistinguishable from that of placebo. Other adverse effects included dermatological symptoms and headaches, which were similar in frequency between placebo and treatment groups ${ }^{10}$. Generally, due to low solubility of silybin (ca $0.5 \mathrm{~g} / 1 \mathrm{H}_{2} \mathrm{O}$ ), it is virtually impossible to reach its toxic concentrations in vivo. Silybin and related flavonolignans displayed inhibition of the catalytic activities of cytochrome P450 (CYP) isoenzymes in vitro in concentrations greatly exceeding physiologically reachable ones ${ }^{98,127}$. It was also shown that silybin does not interfere with the expression of CYP1A2 and CYP3A4 $\left(\right.$ ref. $\left.^{128}\right)$. These findings imply that no adverse effects of si- lymarin/silybin in terms of drug-drug interactions should be expected. However, further study of mechanisms of action and well-designed clinical trials with detailed reporting of adverse effects and components of potential causality are needed.

Recently, silymarin/silybin received attention due to its alternative beneficial activities that are not directly bound to its hepatoprotective and/or antioxidant (radical scavenging) effects. These include mostly anticancer and chemopreventive actions, as well as hypocholesterolemic, cardioprotective, neuroactive and neuroprotective activities. Moreover, the extent of its application has been broadened to other organ systems besides liver and GIT. Silybin seems to be prospective also in treatment of pancreas problems and balancing glycemia, treatment of lung problems and kidney diseases, treatment of various disorders of prostate including adenocarcinoma, and last but not least in dermatology and cosmetics. This is linked to discovery of numerous new effects of silybin and its derivatives on cellular and molecular level, as e.g., estrogenic activity, modulation of drug transporters (P-glycoprotein) and specific action on DNA-expression, for example, via suppression of nuclear factor NF- $\mathrm{B}$. These discoveries are also linked to the progress in silybin chemistry and pharmacology, as e.g., separation and structure determination of silybin diastereomers and synthesis of new derivatives with better and/or altered pharmacokinetic and pharmacodynamic parameters.

Growing interest in new activities of silybin/silymarin in non-traditional applications is documented by the fact that within our millennium (in recent 5 years) around 400 new papers on this topic have been published.

\section{Silybin/silymarin as chemoprotective and anticancer agents}

Application of silybin/silymarin as a chemoprotective and canceroprotective agent could be considered in the first view for its antiradical potential and consequently for its cytoprotective activity. This is partly true, however, it is becoming increasingly apparent that other effects play their role here as well.

Owing to its chemopreventive effect silybin/silymarin inhibits carcinogenic action of many chemicals ${ }^{20}$. Silybin significantly decreased the incidency of urinary bladder neoplasms and preneoplastic lesion in the initiation and post-initiation phase of the induction by $\mathrm{N}$-butyl- $\mathrm{N}$-(4-hydroxybutyl) nitrosamine ${ }^{14}$. This compound also significantly limited azoxymethane-induced colon carcinogenesis in rats $^{15}$. Silymarin inhibited skin carcinogenesis induced by benzoyl peroxide or 12-O-tetradecanoylphorbol-13acetate $^{16-19}$.

Silybin, however, also acts on the receptor level affecting various processes involved either in cancerogenesis or in the cancer proliferation. Modulations of various mitogenic, signalling and cell-cycle regulators by silybin were observed $^{20-27}$. In the human prostate carcinoma silymarin inhibits mitogenic signalling pathways and alters cell cycle regulators ${ }^{28}$, leading to growth inhibition and death of androgen-independent prostate carcinoma cells ${ }^{29}$. An- 
other mechanism of this tumour inhibition by silybin was identified to be insulin-like growth factor-binding protein 3 expression $^{30}$. Some steroid hormone-dependent tumors are also inhibited: both silymarin and silybin elicit antiandrogenic activity in the prostate cancer cell line LNCaP (ref. $^{31,32}$ ). Anti-angiogenic activity of silybin/silymarin described in human umbilical vein endothelial cells (HUVEC) was dose-dependent and associated with a decrease of vascular endothelial growth factor (VEGF) ${ }^{33}$. This finding was later confirmed in human ovarian cancer ${ }^{34}$ - here the analysis suggests that downregulation of the vascular endothelial growth receptor 3 (VEGR) and upregulation of angiopoietin-2 are potential mechanisms responsible for its activity.

\section{Silybin/silymarin in adjuvant therapy of cancer}

One of the most promising activities of silybin is its anticancer activity and potential use of this compound as an adjuvant in the cancerostatic therapy by other chemotherapeutics. Here, silybin acts mainly as an antioxidant to protect tissues against the oxidative stress generated by chemotherapeutics and mainly to eliminate their hepatotoxicity. However, antioxidative action should be balanced to avoid lowering of the anticancer activity ${ }^{35}$.

As with any adjunct therapy, there is a potential for interactions between chemotherapy drugs and silybin/silymarin although no adverse effects have been seen in laboratory studies. There is one published case report of the use of silymarin in a 34-year-old woman with promyelocytic leukemia ${ }^{36}$. During an 18-month maintenance chemotherapy period consisting of treatment with methotrexate and 6-mercaptopurine, the course was complicated by repeated interruptions and dose-modifications for liver toxicity. The patient was then given $800 \mathrm{mg}$ of silymarin in conjunction with the methotrexate and 6-mercaptopurine chemotherapy. During the 4 months of treatment with silymarin, the patient had normal liver aminotransferase levels and there was no further interruption of therapy. No adverse effects were reported.

Silybin enhanced the cytotoxicity of cisplatin in ovarian cancer cells and increased the cytotoxicity of doxorubicin in MCF-7 doxorubicin-resistant breast-cancer cells ${ }^{37}$. Effects of cisplatin in combination with silybinphospholipid complex (IdB 1016) were tested against human ovarian cancer cells (A2780) and in the in vivo experiments in mice ${ }^{38}$. Silybin alone up to $10 \mu \mathrm{M}$ was unable to produce a relevant growth inhibition of A2780 cells, whereas cisplatin was effective, giving an $\mathrm{IC}_{50}$ value of $0.5 \mu \mathrm{M}$. When silybin was combined with cisplatin, a dose-dependent and statistically significant increase of the cisplatin activity was observed, yielding $\mathrm{IC}_{50}$ values of 0.35 and $0.263 \mu \mathrm{M}$ at silybin concentrations of 1 and $10 \mu \mathrm{M}$, respectively. The same trend was observed for in vivo experiments. Administration of both drugs resulted in a potentiation of the antitumour activity. Interestingly, mice receiving the combination recovered earlier in terms of body weight loss as compared to cisplatin treated mice. Finally, the antiangiogenic effect of IdB 1016 in the in vivo experimental model was demonstrated, which further contributed to reducing the tumour growth.

Silybin protection against cisplatin-induced nephrotoxicity was demonstrated in rats ${ }^{39}$. Infusion of silybin before cisplatin results in a significant decrease in glomerular (indicated by creatinin clearance and serum urea level) and tubular kidney toxicity (excretion of brush-border enzymes and magnesium). Inhibition of the antitumour activity of cisplatin and also 4-hydroperoxyfosfamide by co-administration of silybin was excluded in the in vitro experiments with three human testicular cancer cell lines.

Cisplatin toxicity in cultured renal tubular epitelial cells (LLC-PK1) was partly reduced by the pretreatment with quercetin, but other flavonoids tested (catechin, silybin, rutin) were not effective ${ }^{40}$. Here, we may speculate that due to their structural similarity 2,3-dehydrosilybin carrying the quercetin motif in its molecule may be also effective.

Silybin enhances the therapeutic potential of doxorubicin, cisplatin and carboplatin in both estrogen-dependent and -independent human breast carcinoma cells (MCF-7 and MDA-MB468) ${ }^{41}$. When tested alone, each of the four agents showed growth inhibition in both cell lines in a dose- and a time-dependent manner. Based on their growth inhibitory effects, several combinations of silybin (25-100 $\mu \mathrm{M})$ with doxorubicin $(10-75 \mathrm{nM})$, cisplatin $(0.2-2 \mu \mathrm{g} / \mathrm{ml})$ or carboplatin $(2-20 \mu \mathrm{g} / \mathrm{ml})$ were next assessed for their synergistic, additive and/or antagonistic efficacy towards the cell growth inhibition and apoptotic death. The strongest synergistic effects for cell growth inhibition were evident at the silybin dose of $100 \mu \mathrm{M}$ plus $25 \mathrm{nM}$ doxorubicin, in both the cell lines. In quantitative apoptosis studies, combination of silybin with doxorubicin resulted in much stronger apoptotic death compared to each agent alone in both cell lines. Silybin combined with cisplatin showed no additional apoptotic effect in either cell line. Similarly, silybin plus carboplatin combination showed a stronger apoptotic effect only in MCF-7 cells.

Silybin/silymarin is quite often used as a complementary alternative medicine in patients infected with HIV and thus it is necessary to know whether or not it may influence the antiretroviral therapy by the protease inhibitor indinavir. Pharmacokinetic study with healthy volunteers confirmed that silymarin has no apparent effects on indinavir plasma concentrations ${ }^{42,43}$.

An interesting study of interaction of silybin and adriamycin in the unicellular eukaryote Tetrahymena thermophila demonstrated that silybin $(1 \mathrm{mg} / \mathrm{ml})$ completely prevents effects of adriamycin on the cell and biomass production ${ }^{44}$. Adriamycin transport to the cells was not inhibited by silybin. Other "standard" antioxidants as butyl hydroxyanisol or superoxide dismutase-catalase- $N$ acetylcystein cocktail did not prevent adriamycin activity. It was, therefore, concluded that the inhibitory activity of silybin does not arise from its antioxidant activity but more probably from stimulation of RNA synthesis impaired by the adriamycin-DNA interaction. 
The use of milk thistle should not be recommended outside the context of well-designed clinical trials in patients with cancer who are concurrently receiving chemotherapy. Investigators need to assess carefully if the benefits of this therapy outweigh the risks and, especially, ascertain if the milk thistle will confer a benefit to the patient without decreasing survival by inhibiting the efficacy of chemotherapy.

\section{Neuroprotective and neurotropic activities of silybin/silymarin}

Silybin or silymarin may be useful in treatment and prevention of some neurodegenerative and neurotoxic processes, partly due to its antioxidative activity, but also other, so far unknown, mechanisms. Wang et al. ${ }^{45}$ demonstrated that silymarin could effectively protect dopaminergic neurons against lipopolysaccharide (LPS)-induced neurotoxicity by inhibiting an activation of microglia that represent resident macrophage-like population of brain cells acting in host defence and tissue repair in the CNS. There is growing evidence that activated microglia contribute to neuropathological changes in several CNS diseases (multiple sclerosis, Parkinson's disease, Alzheimer's disease, AIDS dementia). Silymarin also inhibits the production of inflammatory mediators, such as tumor necrosis factor- $\alpha$ (TNF- $\alpha$ ) and nitric oxide and thus reduces damage to dopaminergic neurons. Further on, these authors found that silymarin in a dose-dependent manner reduced the production of inducible nitric oxide synthase in LPSstimulated BV-2 cells (model of microglia activation). It was suggested that the inhibitory effect of silymarin on microglia is mediated through the inhibition of nuclear factor $\kappa \mathrm{B}(\mathrm{NF}-\kappa \mathrm{B})$ activation.

An extract from Silybum marianum seeds was tested on the differentiation and survival of cultured neural cells (rat PC-12 pheochromocytoma cell line). The extract enhanced the differentiation of PC-12 cells and prevented apoptosis following nerve growth factor (NGF) withdrawal. Moreover, the extract protected primary hippocampal neurons against oxidative stress-induced apoptosis ${ }^{46}$.

Unfortunately these results have somehow limited validity as the authors used self-prepared crude extract from S. marianum seeds without any standardisation or analysis. Thus, one can only speculate which component(s) of rather complex extract is responsible for the above effect.

Series of flavonoids and hydroxycinnamates was found to attenuate neuronal damage induced by oxidised low-density lipoproteins that are normally able to enter neuronal cells and in a dose-dependent manner elicit neurotoxicity (DNA fragmentation and cell lysis) ${ }^{47}$. Even though silybin was not included in this study, its activity within this system is expected as well.

Silymarin (PHYTO - a complex with phosphatidyl choline) has partly protective activity on foetal brain and liver in ethanol treated pregnant rats ${ }^{48}$. However, these findings need more detailed study. No significant protective effects of silybin on $N$-methyl-4-phenylpyridinium ion induced-neurotoxicity and on L-glutamate induced cell death in PC-12 neuronal cells were found by Mazzio et al. ${ }^{49}$.

An interesting study aiming at neuro-immunomodulation mediated by silybin was accomplished by Sakai et al. ${ }^{50}$. Major histocompatibility complex (MHC) I is usually suppressed in neuronal cells and neuroblastoma cells and this may lead to persistent viral infections. Induction of MHC I molecules in neuronal cells can stimulate the immune system to be able quickly to identify intracellular pathogens by cytotoxic $\mathrm{T}$ cells and remove the viruses from the central nervous system. Silymarin treatment resulted in the expression of MHC I in cells. Therefore, it was proposed that silymarin may be useful in the treatment of encephalitis. More studies, both in vitro and in vivo are, however, required.

\section{Silybin/silymarin in treatment and prevention of gastrointestinal problems}

Silybin is naturally best known as hepatoprotectant and choleretics, however, also other gastrointestinal problems can be treated and/or prevented by its preparations.

In pancreas silybin can act mainly as chemoprotectant and can also stimulate recovery after intoxication leading to damages.

Silymarin was used in rats treated with alloxan ${ }^{51,52}$. Alloxan causes severe necrosis of pancreatic $\beta$-cells, with the consequent lack of insulin secretion. For this reason it has been widely used to induce experimental diabetes mellitus, and many studies have been performed using this model to explore pancreatic damage. It was suggested that alloxan induces the production of $\mathrm{H}_{2} \mathrm{O}_{2}$ and of some free radicals such as $\mathrm{O}_{2}^{-}$and $\mathrm{OH}$, which produce cellular damage followed by cell death. There is a strong support for the suggestion that reactive oxygen species play a relevant role in the etiology and pathogenesis of diabetes and its long-term effects. Therefore, the above model was considered adequate for the study of pathology such as diabetes mellitus. It was found that silymarin was able to prevent a rise in both plasma glucose and pancreatic lipid peroxidation in the hyperglycemic rats ${ }^{51}$. Thus, it was suggested that the protective effect could be ascribed to silymarin either due to its antioxidant properties or to an increase of plasma and pancreatic glutathione concentrations, or both. Silymarin also stimulated pancreatic activity of antioxidant enzymes: glutathione peroxidase, superoxide dismutase and catalase ${ }^{52}$. Silymarin had not only a protective effect on rat alloxan-induced diabetes mellitus but it also induced pancreas recovery ${ }^{53}$. The seriousness of human diabetes mellitus as the world health problem is growing due to the fact that at least 150 million people are affected; therefore, there is the necessity to search for new drugs. The existing ones only favor insulin release or control blood glucose level but do not recover the endocrine pancreatic function. Silymarin represents a new possibility in the treatment of diabetes mellitus, not only for the enhanced insulin levels but also for the pancreatic function recovery. Nevertheless, more studies are required to prove its beneficial properties in human diabetes mellitus. 
Matsuda et al. ${ }^{54}$ recently studied another damaging mechanism of pancreatic $\beta$-cells in relation to silymarin. They investigated effect of silymarin on interleukin $1 \beta$ (IL-1 $\beta$ ) and/or interferon- $\gamma$ (IFN- $\gamma$ )-induced $\beta$-cell damage using RINm5F cells (insulinoma cell line) and human islets. IL-1 $\beta$ and/or IFN- $\gamma$ brought about $\beta$-cell damage in a time-dependent manner in the insulinoma cells. Silymarin dose-dependently inhibited both cytokine-induced NO production and cell death. Also in the human islets silymarin prevented IL- $1 \beta+$ IFN- $\gamma$-induced NO production and $\beta$-cell dysfunction. These cytoprotective effects of silymarin appeared to be mediated through the suppression of c-Jun $\mathrm{NH}_{2}$-terminal kinase and Janus kinase/signal transducer and activator of transcription pathways. Silymarin also inhibits production of inflammatory cytokines, such as IL-1 $\beta$, IFN- $\gamma$, and IFN- $\alpha$ from macrophages or T-lymphocytes ${ }^{55,56}$, which probably initiate the destruction of $\beta$-cells in the development of type 1 diabetes. Therefore, silymarin may be useful as a therapeutic agent for the type 1 diabetes mellitus.

Silybin was also tested for the protection of cyclosporin A toxicity $(10 \mathrm{mg} / \mathrm{kg} /$ day $i . p$. $)$ in both endocrine and exocrine pancreas in rats $^{57}$. At the end of testing period (day 9) blood glucose levels were significantly higher in rats treated with cyclosporin, while silybin itself did not affect the glucose level. In vitro, insulin secretion was inhibited after treatment with silybin but amylase secretion was not affected. After treatment with cyclosporin both insulin and amylase secretion were reduced. Silybin inhibits the glucose-stimulated insulin release in vitro, whithout affecting the blood glucose concentration in vivo. This combination could be useful in the treatment of non-insulin-dependent diabetes mellitus. Moreover, silybin also protects the exocrine pancreas from cyclosporin toxicity.

In this connection it is interesting to mention that decoction from aerial parts of Silybum marianum is used in traditional medicine in Morocco in the treatment of diabetes mellitus and Maghrani et al. ${ }^{58}$ confirmed its action in rats with experimental type 1 diabetes.

The intestinal anti-inflammatory activity of several doses of silymarin was tested in the acute stage of trinitrobenzenesulfonic acid (TNBS) model of rat colitis ${ }^{59}$. Obtained results show that the oral pre-treatment with $50 \mathrm{mg} / \mathrm{kg}$ of silymarin significantly attenuated macroscopic colonic damage as well as reduced colonic myeloperoxidase activity compared to nontreated colitic animals. The beneficial effect was accompanied by an improvement in the colonic oxidative status, which was altered in colonic inflammation, by preventing glutathione depletion and reducing malonyldialdehyde production. This suggests that the wellknown antioxidant properties of silymarin can participate in its intestinal anti-inflammatory activity. In addition, preservation in the colonic absorptive function was also observed, and this effect can also account for the colonic protective effect observed in this model of acute colitis.

The above effects are obviously caused by the antioxidant activity of silymarin, but silybin and other component of silymarin can also act in colon as specific inhibitors of intestinal bacterial $\beta$-glucuronidase ${ }^{60}$. This effect may improve hepatoprotection during metabolism of xenobiotics with toxic metabolites excreted via bile in the form of glucuronides by preventing their enterohepatal circulation.

Another application of silybin in the treatment of colon diseases is the application of its known cancerostatic and anti-angiogenic properties. Silymarin and pure silybin significantly inhibit the in vitro cell growth of colon cancer (LoVo cell line) and endothelial cell lines (EA.hy 926)(ref. $\left.{ }^{61}\right)$. Cytotoxic assays were done also in the co-culture of endothelial and cancer cells and proved that both silymarin and silybin inhibit differentiation, chemotaxis and migration of endothelial cells. Secretion of vascular endothelial growth factor was decreased by silybin $(6.6 \mu \mathrm{M})$ to $50 \%$ value. The effects of silybin and silymarin (both very similar) were found to be comparable with thalidomide that has been used recently in the anticancer therapy as anti-angiogenic agent.

Silybin has been shown to have antiproliferative and apoptotic effects towards human colon carcinoma HT-29 cells $^{62}$. Silybin treatment of cells at $50-100 \mu \mathrm{g} / \mathrm{ml}$ doses resulted in a moderate to very strong growth inhibition in a dose- and time-dependent manner due to the G0/G1 arrest in cell cycle progression; higher dose and longer treatment time also caused the $\mathrm{G} 2 / \mathrm{M}$ arrest. This very detailed study shows that silybin activity involves the modulation of cyclin-dependent kinases (CDK), cyclins and other CDK regulators leading to $\mathrm{G} 0 / \mathrm{G} 1$ and $\mathrm{G} 2 / \mathrm{M}$ arrests.

\section{Silybin/silymarin in treatment and prevention of nephropathy}

Use of silybin in nephropatic processes has a similar potential as in most of the above organs, i. e. chemoprotectant and antioxidant. With expanding waiting lists for kidney transplantations it appears crucial to improve the long-term allograft outcome. Cold ischaemia and reperfusion during kidney transplantation are associated with the release of free oxygen radicals and damage of renal tubular cells. Series of flavonoids was tested for enhancement of cell survival. Pretreatment with quercetin significantly improved the survival rate of cells but many other flavonoids including silybin were ineffective ${ }^{63}$.

Silybin was found to have a similar stimulatory effect to the kidney cells (Vero line, nonmalignant kidney cells from monkeys) as described in liver cells ${ }^{64}$. Proliferation rate, biosynthesis of protein and DNA, and the activity of lactate dehydrogenase were stimulated by silybin and silychristin, whereas isosilybin and silydianin were ineffective. In the kidney cells damaged in vitro by paracetamol, cisplatin, and vincristin it was demonstrated that administration of silybin before or after the chemical-induced injury can reduce or avoid nephrotoxic effects ${ }^{64}$.

Comparable effects of silymarin and picroliv (standardized iridoid glycoside fraction of Picrorhiza kurroa) against aflatoxin $\mathrm{B}_{1}$ intoxication of rat kidney and liver were found by Rastogi et al. ${ }^{65}$. This intoxication is expected to proceed via oxidative damage of the cells by lipid peroxidation, thus the antioxidation effect of both antioxidants is quite obvious. 
Another dangerous mycotoxin with nephrotoxic activity - fumonisin $B_{1}$ (produced by various fusaria on corn) can be antagonised by silymarin in porcine renal epitelial cells $\left(\right.$ LLC-PK $\left._{1}\right)\left(\right.$ ref. $\left.^{66}\right)$. Silymarin prevents this intoxication by modulation of TNF- $\alpha$ expression or signal downstream of the inhibition of ceramide synthase whose deregulation represents the main toxigenic effect of fumonisin $B_{1}$.

Silybin was used in the treatment of 30 patients suffering from end-stage diabetic nephropathy $(\mathrm{ESDN})^{67}$. Diabetic and especially hemodialysis patients are at increased risk of oxidative cell damage. Under these conditions body radical scavengers - free thiols (GSH) are found to be reduced. The lowered total intracellular thiol levels correlated directly to a significantly diminished T-cell activation and elevated synthesis of TNF- $\alpha$ in the patient group. The treatment with silybin or silymarin (Legalon) led to a restoration of the thiol status within $72 \mathrm{~h}$ both in vitro and in vivo. This effect showed a biphasic kinetics that first utilized cell surface thiols and secondly intracellular thiols. In parallel, the T-cell activation was improved substantially along with a significant decrease in TNF- $\alpha$ release. These data provide the rationale for clinical trials using flavonolignans in ESDN to normalize immunoregulatory defects via restoration of the cellular thiol status.

\section{Silybin/silymarin in treatment and prevention of cardio-pulmonary problems}

Amiodarone is a very potent antiarrhythmic drug with almost ideal antiarrhythmic properties; however, its use is limited by frequent and sometimes serious side effects. Free radical reactions play rather important role in the pathogenesis of amiodarone toxicity. Potential mechanisms of amiodarone toxicity include direct cytotoxicity, development of lysosomal phospholipidosis, indirect immunologically mediated toxic effects and membrane destabilization ${ }^{68}$. Administration of silybin together with amiodarone decreases significantly lysosomal phospholipidosis ${ }^{69}$ and this effect is further enhanced in combination with vitamin E (ref. $\left.{ }^{70}\right)$. During the amiodarone treatment (rats) silymarin itself as well as in combination with vitamin E significantly decreased conjugated diene concentration ${ }^{71}$ but did not attenuate antiarrhythmic activity of amiodarone ${ }^{72}$.

Silybin can also be very effective in the cardioprotective application during the cancer treatment with cardiotoxic drugs, as e. g., doxorubicin (Adriamycin), especially in children and old people. The use of this chemotherapeutic is limited by its cardiotoxicity that is partly mediated by oxidative stress and apoptosis induction. The ability of silymarin and its isolated components to protect cardiomyocytes (rat) against doxorubicin-induced oxidative stress is mainly due to their cell membrane stabilizing effect and radical scavenging potency ${ }^{73}$. Silymarin significantly reduces damage to rat heart microsomes and mitochondria by a doxorubicin- $\mathrm{Fe}^{3+}$ complex ${ }^{74}$.

Combination of doxorubicin with silybin was tested also in the lung tumor treatment ${ }^{75}$. Oral silybin suppressed the human non-small-cell lung carcinoma A549 xenograft growth (athymic BALB/c $n u / n u$ mice) and enhanced the therapeutic response of doxorubicin together with prevention of doxorubicin-caused adverse health effects. Doxorubicin itself increased the NF- $\mathrm{BB}$ DNA binding activity as one of the possible mechanisms for chemoresistance in A549 cells that was inhibited by silybin in the combination treatment. These data indicate that silybin is a potential agent for lung tumor growth inhibition, i. e. applied either independently or in combination chemotherapy with cancerostatic agents, e. g. anthracycline drugs. These findings together with other reports support the preventive effect of silybin against doxorubicin-caused systemic toxicity; however, more studies in different models are needed.

Moreover, silybin exhibits a dose- and time-dependent inhibitory effect on the invasion and motility of highly metastatic A549 cells in the absence of cytotoxicity ${ }^{76}$. Silybin treatment may decrease the expressions of metalloproteinase-2 (MMP-2) and urokinase plasminogen activator (u-PA) in a concentration- and time-dependent manner and enhance the expression of tissue inhibitor of metalloproteinase-2 (TIMP-2). Further analysis with semiquantitative RT-PCR showed that silybin may regulate the expressions of MMP-2 and u-PA on the transcriptional level, while the TIMP-2 expressions on the translational or posttranslational level.

Silymarin has also a protective effect in the early phase of allergic asthma, an effect, which may be related to a negative influence of the flavonoid on bronchial responsiveness to histamine ${ }^{77}$. Silymarin showed a moderate protection against the bronchospasm induced by aerosol antigen challenge in sensitized guinea-pigs. This action can be explained by the various biological effects of silymarin, e.g. its membrane-stabilizing effect, anti-inflammatory activity and inhibition of the arachidonic acid pathway. Protective effect of silymarin seems to be due to an indirect mechanism that reduces airway responsiveness to histamine, and consequently the immediate anaphylactic response.

\section{Silybin/silymarin in skin protection}

Skin exposure to solar UV radiation induces a number of skin disorders, including erythema, edema, sunburn cell formation, hyperplasia, immune suppression, DNA damage, photoaging, melanogenesis and skin cancers. It is well documented that UV irradiation, both its UVB (290$320 \mathrm{~nm}$ ) and UVA (320-400 nm) component, induces the generation of reactive oxygen species (ROS), which create the oxidative stress in skin cells and play an important role in the initiation, promotion and progression of skin aging and carcinogenesis ${ }^{78}$. Thus the use of antioxidants, namely naturally occurring herbal compounds, is receiving considerable interest to protect skin from adverse biological effects of solar UV radiation ${ }^{78,79,129}$.

Both silymarin and silybin have been shown to exhibit preventive effects against photocarcinogenesis in various animal tumor models. Topical application of silymarin to mouse skin (SKH-1 hairless mouse model) reduced UVBinduced tumor incidence, tumor multiplicity and tumor size compared to those of non-treated animals ${ }^{80}$. Silybin 
inhibited photocarcinogenesis in mice when applied topically or administered in the diet ${ }^{81}$.

Cutaneous photoprotection mechanisms triggered by silymarin and silybin are numerous and demonstrate mainly their ability to reduce and suppress harmful effects of solar UV radiation, such as UV-induced oxidative stress, inflammation, immune responses and DNA damage as well as induction of apoptosis.

Topical application of silymarin suppressed intracellular production of hydrogen peroxide and nitric oxide and reduced depletion of catalase activity in UVB-irradiated mouse skin (SKH-1 hairless mice). In addition, silymarin inhibited expression of cyclooxygenase-2 (COX-2) and its prostaglandin metabolites $\left(\mathrm{PGE}_{2}, \mathrm{PGF}_{2}, \mathrm{PGD}_{2}\right)$, which have been implicated in tumor promotion ${ }^{80}$. Silymarin and silybin have been also shown to prevent oxidative stress induced by UVA-irrradiation in human immortalized cutaneous cells (HaCaT keratinocytes)( ref. $^{82}$ ).

In the SKH-1 hairless mice silymarin inhibited UVBinduced skin edema, formation of sunburn and apoptotic cells, prevented UVB-induced infiltration of inflammatory leukocytes, and significantly reduced the activity of myeloperoxidase, a marker of tissue infiltration ${ }^{80,83}$. Studies have also indicated that topical treatment of silymarin to mouse skin prevents UVB-induced suppression of contact hypersensitivity response to contact senzitizer dinitrofluorobenzene. It has been shown that prevention of UVB-induced suppression of contact hypersensitivity by silymarin is mediated through the inhibition of interleukin IL-10 production and suppression of infiltration of $\mathrm{MHC}^{+} \mathrm{CD} 11 \mathrm{~b}^{+}$cells in irradiated skin ${ }^{83}$.

Photochemical damage to DNA, predominantly in the form of cyclobutane-pyrimidine dimers (CPD), plays an important role in immune suppression and skin cancer initiation. Topical application of silymarin prevented UVBinduced CPD formation in mouse $\operatorname{skin}^{84}$. Induction of apoptosis together with the inhibition of DNA synthesis, cell proliferation and cell cycle progression has been suggested as in vivo molecular mechanism of silybin efficacy against photocarcinogenesis by Mallikarjuna et al. ${ }^{81}$.

Silybin effect on UVB-induced apoptosis was examined in human epidermoid carcinoma A 431 cells. It was shown, that silybin treatment prior to radiation causes a further increase in apoptosis, whereas post-treatment protects against apoptosis. Differential effects of silybin on UVB-induced apoptosis involved the modulation of mitochondrial apoptotic machinery (Bcl-2 family members, cytochrome c), caspases activation and mitogen-activated protein kinase (MAPK) signaling ${ }^{85}$. Dual efficacy of silybin on apoptosis was observed also in human keratinocytes $(\mathrm{HaCaT})^{86}$. Silybin afforded strong protection against UVB-induced apoptosis at lower doses (15 and $30 \mathrm{~mJ} / \mathrm{cm}^{2}$ ), which was completely lost at a higher dose $\left(120 \mathrm{~mJ} / \mathrm{cm}^{2}\right)$, and, in fact, increase in apoptosis together with strong down-regulation of activated protein-1 (AP-1) DNA binding activity were observed. These findings suggest that silybin could protect normal human skin keratinocytes against sunburn or apoptosis when the damage is moderate. When the UVB damage is severe, silybin causes apoptotic cell death, which might be of significance in deleting DNA damaged cells from cell cycle progression.

Current experimental observations indicate that silymarin/silybin may be beneficial in skin photoprotection against sunburn response, DNA damage and immunosuppression. However, further studies are required in human system to determine cellular uptake, distribution and longterm effects in the skin.

\section{Silybin/silymarin interactions with steroid hormone receptors}

A number of natural compounds have been found to modulate nuclear hormone receptor-dependent gene expression. Upon binding as ligands, they either activate nuclear receptors or compete with natural hormones. Antiestrogenic and antiandrogenic effects of some polyphenolic compounds lead to inhibition of steroid hormone receptor-dependent proliferation of cancer cells. Both silymarin and silybin elicit antiandrogenic activity in the prostate cancer cell line LNCaP (ref. ${ }^{31,32}$ ). Several plant flavonoids or other polyphenolic compounds have been shown to elicit anti/estrogenic activity both in vitro and in vivo $^{87-89}$. Silybin can bind to a purified steroid receptor ${ }^{90}$ and estrogenic effects of silymarin have been observed in ovariectomised rats in the 30-day uterotrophic assay. However, this latter finding was not confirmed in the ovariectomised rats after subcutaneous treatment with silymarin $^{91}$.

We found recently ${ }^{92}$ that silymarin elicited partial ER activation and silybin B was probably responsible for a majority of the weak ER-mediated activity of silymarin, where as its diastereomer silybin A was found to be inactive. This is probably the most fundamental finding on the estrogenic activity of silybin and also the first study describing effects of separated silybin diastereoisomers A and $\mathrm{B}$ towards receptors in biological systems.

\section{Silybin/silymarin in modulation of drug transporters}

Multidrug resistance (MDR) represents an increasing problem in the treatment of cancer and bacterial infections. It often appears after prolonged exposure of cells to a single drug and is often characterized by its resistance to a series of structurally unrelated compounds. One important resistance mechanism involves drug depletion in cells by membrane efflux proteins, for example P-glycoprotein (Pgp) in mammalian cells, Bmr in Bacillus subtilis, and NorA in Staphylococcus aureus.

Pgp is a $170 \mathrm{kDa}$ phosphorylated glycoprotein encoded by human MDR1 gene. It is responsible for the systemic disposition of numerous structurally and pharmacologically unrelated lipophilic and amphipatic drugs, carcinogens, toxins and other xenobiotics in many organs, such as the intestine, liver, kidney, and brain. Like cytochrome P450, Pgp is vulnerable to inhibition, activation, or induction by herbal constituents ${ }^{93}$. Silymarin, besides some other plant substances (curcumin, ginsenosides, piperine, catechins), was found to be an inhibitor of Pgp function.

Silymarin increased daunomycin accumulation in Pgp-positive cells, but not in Pgp-negative cells, in a 
drug concentration- and Pgp expression level-dependent manner ${ }^{94}$. Silymarin potentiated doxorubicin cytotoxicity in Pgp-positive cells, while it inhibited Pgp ATPase activity and azidopine photoaffinity labeling of Pgp, suggesting a direct interaction with Pgp substrate binding ${ }^{94}$. Silymarin (and biochanin A - isoflavone from red clover extract) increased the accummulation of digoxin and vinblastin in human intestinal Caco-2 cells in a concetration-dependent manner by inhibition of their Pgp mediated efflux ${ }^{126}$. In human prostate carcinoma DU 145 cells, silybin potentiated doxorubicin-induced growth inhibition and apoptosis ${ }^{95}$. Incubation of cells with silymarin over $24 \mathrm{~h}$ did not change membrane Pgp levels. Furthermore, silybin and its derivatives were identified as inhibitors of P-glycoprotein ${ }^{96,97}$. This activity is mainly pronounced in the 2,3-dehydrosilybin derivatives carrying prenyl- or geranyl- substituents ${ }^{96}$. These findings indicated that silymarin, silybin and its derivatives may inhibit Pgp-mediated cellular efflux, raising a potential for significant drug interactions with Pgp substrates.

The effect of milk thistle on the pharmacokinetics of the known Pgp substrate indinavir was investigated in healthy volunteers ${ }^{42,43}$. Treatment of milk thistle at $175 \mathrm{mg}$ (equivalent to silymarin $153 \mathrm{mg}$ ) three times per day for 3 weeks caused a $9 \%$ and $25 \%$ reduction in the indinavir AUC and mean trough level, respectively ${ }^{42}$. It thus appeared that the interaction was minimal and should not interfere with indinavir therapy in AIDS patients.

Pgp-like transporter in Leishmania spp. was also found to be inhibited by silybin and namely with its derivative 8-(3,3-dimethylallyl)-dehydrosilybine ${ }^{99}$ that led to the parasite sensitization towards daunomycin.

Silybin also interacts with other drug transporters, e.g., with multidrug resistance-associated protein 1 (MRP1). Influence of silymarin and other flavonoids was tested in human pancreatic adenocarcinoma cell line (Panc-1) on the transport of daunomycin and vinblastin ${ }^{100}$. It was found that silymarin significantly increases accumulation of both drugs in the cells indicating the inhibition of MRP1. It seems that GSH regeneration is involved in this process because in the other study with flavonoids ${ }^{101}$ stimulation of GSH co-transport, ATPase and drug resistance-conferring properties of MPR1 were found to be modulated.

The flavonolignan 5'-methoxyhydnocarpin-D (ref. ${ }^{102,103}$ ) was recently found to be a potent inhibitor of the NorA MDR efflux pump in S. aureus. A number of hydnocarpintype flavonolignans, derivatives of silybin, proved to have a greater potency than the natural isolate, 5'-methoxyhydnocarpin-D (ref. $\left.{ }^{104}\right)$. Silybin itself had a medium inhibitory potency.

The causative agents of sleeping sickness, Trypanosoma brucei rhodesiense and T. brucei gambiense, do not synthesize purines de novo but salvage purine bases and nucleosides from their hosts. A selection of purine analogs and flavonoids were tested for their ability to interfere with adenosine transport. Silybin was a potent, noncompetitive inhibitor of trypanosomal purine transporter TbAT1. Silybin also inhibited melarsen-induced lysis of bloodstream form trypanosomes ${ }^{105}$. This makes silybin a good candidate for antiparasital and/or adjuvant antiparasite treatment.

\section{Silybin/silymarin in regulation of apoptosis and inflammation process}

The molecular bases of the anti-inflammatory and anticarcinogenic effects of silybin/silymarin are yet unknown; they might be related to inhibition of the transcription factor NF- $\mathrm{kB}$, which regulates and coordinates the expression of various genes involved in the inflammatory process, in cytoprotection and carcinogenesis. In particular, NF- $\kappa \mathrm{B}$ contributes to the production of interleukins IL-1 and IL-6, tumor necrosis factor (TNF- $\alpha$ ), lymphotoxin, granulocyte-macrophage colony-stimulating factor (GM-CSF) and interferon (IFN- $\gamma$ ). Furthermore, some of these cytokines, e.g., IL-1 and TNF- $\alpha$ activate NF- $\kappa$ B themselves, thus creating positive feedback. NF- $\mathrm{KB}$ activation occurs on its dissociation from the inhibitory protein I- $\mathrm{KB}$ and its subsequent nuclear translocation. NF-אB seems to be a subject to redox regulation, suggesting thus an important role of antioxidants in its inactivation.

Silymarin was tested in $\mathrm{HaCaT}$ (human keratinocytes) induced with UV light and in HepG2 cells (human hepatoblastoma) induced with okadaic acid and LPS ${ }^{106,107}$ and proved to be highly effective in suppressing NF- $\mathrm{BB}$ binding activity and its dependent gene expression. Compared to other bioflavonoids tested, silymarin inhibits transcription factor NF-kB in very low concentrations $(12 \mu \mathrm{g} / \mathrm{ml})\left(\right.$ ref. $\left.^{107}\right)$.

Manna et al. ${ }^{108}$ studied the effect of silymarin on NF- $\kappa B$ activation induced by various inflammatory agents. Silymarin blocked TNF- $\alpha$-induced activation of NF- $\mathrm{BB}$ in a dose- and time-dependent manner. This effect was mediated through inhibition of phosphorylation and degrada-

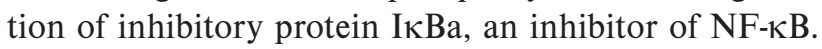
NF-kB-dependent reporter gene transcription was also suppressed by silymarin. Silymarin also blocked NF-kB activation induced by phorbol ester, LPS, okadaic acid, and ceramide, whereas $\mathrm{H}_{2} \mathrm{O}_{2}$-induced NF- $\mathrm{KB}$ activation was not significantly affected. Silymarin also inhibited the TNF- $\alpha$-induced activation of mitogen-activated protein kinase and c-Jun N-terminal kinase and abrogated TNF$\alpha$-induced cytotoxicity and caspase activation. The inhibition of activation of NF- $\mathrm{KB}$ and the kinases may provide in part the molecular basis for the anticarcinogenic and anti-inflammatory effects of silymarin, and its effects on caspases may explain its role in cytoprotection. Like silymarin, the anti-inflammatory drugs sodium salicylate and aspirin are also known to block the activation of NF- $\mathrm{KB}$ by preventing the degradation of $I \kappa B \alpha$. However, silymarin was effective at a100-fold lower concentration than salicylate, suggesting that it is a potent inhibitor without substantial toxicity.

Silybin is also known to induce apoptosis of endotelial cells and to inhibit angiogenesis, which is essential for tumor growth and metastasis. Silybin was found to suppress the growth and induce the apoptosis of ECV304 cells (human umbilical vein endotelial cell line)(ref. ${ }^{109}$ ). The induction of apoptosis by silybin was confirmed by ladder-patterned DNA fragmentation, cleaved and con- 
densed nuclear chromatin and DNA hypoploidy. Silybin could effectively inhibit a constitutive NF- $\kappa$ B activation as revealed by electrophoretic mobility shift assay and NF$\kappa \mathrm{B}$-dependent luciferase reporter study. Consistent with this, silybin treatment resulted in a significant decrease in the nuclear level of p65 subunit of NF- $\mathrm{kB}$. In addition, silybin-treatment caused a change in the ratio of Bax/Bcl-2 in a manner that favors apoptosis. Silybin also induced the cytochrome c release, activation of caspase- 3 and caspase-9 and cleavage of poly(ADP-ribose) polymerase (PARP). These results suggest that silybin may exert, at least partly, its anticancer effect by inhibiting angiogenesis through induction of endothelial apoptosis via modulation of NF- $\kappa \mathrm{B}, \mathrm{Bcl}-2$ family and caspases ${ }^{109}$.

Series of excellent studies from Agarwal's group has demonstrated high efficiency of silybin in the prostate tumor adjuvant treatment. One possible mechanism of this effect is the indirect potentiation of TNF- $\alpha$ action by silybin inhibition of NF- $\mathrm{KB}$ (ref. ${ }^{110}$ ). The studies revealed that silybin is able to inhibit constitutive activation NF- $\kappa B$ in human prostate cancer cell line DU145. Silybin also inhibits TNF- $\alpha$-induced activation of $\mathrm{NF}-\kappa \mathrm{B}$ via $\mathrm{I} \kappa \mathrm{B} \alpha$ pathway and subsequently sensitizes DU145 cells to the TNF- $\alpha$-induced apoptosis.

Silymarin is known to have an anti-atherosclerotic activity. The mechanism responsible for it can be partly explained by the antioxidative protection of cholesteroltransporting lipoproteins but it still partly remains unclear. Silymarin inhibited THP-1 (human monocyte cell line) cell adhesion to human umbilical vein endothelial cells (HUVEC). Silymarin also suppressed the TNF- $\alpha$-induced protein and mRNA expression of adhesion molecules, such as VCAM-1, ICAM-1 and E-selectin, in HUVEC. Moreover, silymarin suppressed the TNF- $\alpha$-induced DNA binding of NF- $\kappa \mathrm{B}$ in HUVECs. Therefore, part of the silymarin anti-atherosclerotic activity is mediated by inhibiting the expression of adhesion molecules ${ }^{111}$.

\section{Stereochemistry of silybin $v$ s biological activity}

Silymarin flavonolignans are biogenetically formed by oxidative addition of coniferylalcohol to taxifolin, whose low stereospecifity gives rise to the whole variety of these isomers. This is why the natural silybin is approximate equimolar mixture of two diastereomers $\mathrm{A}$ and $\mathrm{B}$, whose analytical separation is quite feasible ${ }^{112}$, but preparatory separation is extremely complicated. Semipreparatory

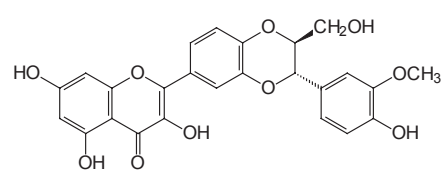

2,3-Dehydrosilybin B

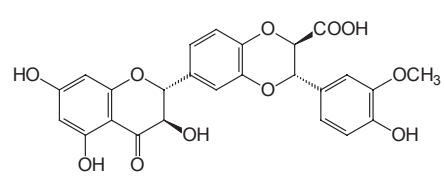

Silybinic acid B separation of silybin diastereomers was accomplished by silybin glycosylation, followed by column separation of the glycosides of pure silybin diastereomers and their hydrolysis ${ }^{113}$. This enabled for the first time to determine spectral characteristics of optically pure silybins (OR, $\mathrm{CD},{ }^{13} \mathrm{C}$ and ${ }^{1} \mathrm{H}$ NMR etc.). Absolute configuration of both silybin A and B (Fig. 1) was determined by Lee and $\mathrm{Liu}^{114}$. In the same year Kim et al. ${ }^{115}$ published independently but incorrectly the absolute configuration of both silybin diastereomers.

Weyhenmeyer et al. ${ }^{116}$ published a study on the pharmacokinetics of silybin diastereomers. They, however, used natural silybin (a mixture of both silybins) and measured plasma profiles of - at that time unidentified - diastereomers determined by HPLC. They have found that plasma concentration of one unconjugated silybin diastereomer is ca $3 \mathrm{x}$ higher than the concentration of the other one. This difference was presumably caused by a different conjugation rate (glucuronidation) of respective silybin diastereomers. This assumption was later corroborated by us ${ }^{117}$ by the preparation of silybin metabolites, e.g., respective glucuronides, from optically pure silybin and by analysis and assignments of silybin metabolites in humans.

There are only scarce data on the pharmacological activity of respective isolated silybins A, B (vide infra). Diastereomers of silybin are very important especially in the interaction with receptors or other anisotropic systems. We have recently demonstrated ${ }^{92}$ a clear proof of it: silybin B interacts with estrogenic receptor, whereas its diastereomer silybin A was found to be inactive (see p. 35).

Aspects of optical purity of silybin and also other flavonolignans from the silymarin complex were largely neglected. However, should silymarin be used for applications other than as a mere antioxidant in an isotropic milieu (e.g., in solution) the stereochemistry will play an extremely important role and respective biological activities will have to be studied also with optically pure compounds.

\section{New silybin derivatives}

The bioavailability and therapeutic efficiency of silybin is rather limited by its very low water solubility (430 mg/1). The solubility was improved by the preparation of silybin 3,23-O-bis-hemisuccinate ${ }^{118}$ that enabled intravenous application of silybin (Legalon-SIL, Madaus) for the treatment of acute liver intoxication by mycotoxins. Glycosylation was demonstrated to be another way of improving silybin solubility ${ }^{113,119,123,124}$. Bioavailability of silybin has been also substantially improved by preparation of silybin-phosphatidylcholine complex (IdB 1016, Indena). This complex has better bioavailability than pure silybin/ silymarin as recently demonstrated by Škottová et al. ${ }^{120}$ by pharmacokinetic study with iodine-labeled silybin.

Carboxylic acids derived from silybin and 2,3-dehydrosilybin (Fig. 3) with improved water solubility were prepared by selective oxidation of parent compounds and a new inexpensive method for preparation of 2,3dehydrosilybin from silybin was developed and optimised and their antioxidant and cytoprotective activities were

Fig. 3 
determined $^{121}$. 2,3-Dehydrosilybin is more lipophilic and less water-soluble than silybin, which is prerequisite for its application in lipophilic milieu (cell membrane antioxidant, ointments). However, respective carboxylic derivative combines its considerably better antioxidative properties together with improved hydrophilicity.

The presence of 2,3-double bond in the C-ring of flavonoid molecule is connected with an increase in scavenging/antioxidative potency of the compounds. 2,3Dehydrosilybin is obviously a superior silybin derivative both from the point of view of radical scavenging and antilipoperoxidant activity.

Series of selectively alkylated (prenylated and geranylated) derivatives of 2,3-dehydrosilybin were prepared ${ }^{96,122}$ and they were found to be significant inhibitors of P-glycoprotein (see p. 36).

\section{ACKNOWLEDGEMENT}

This work was supported by the grant No. 303/02/1097 from the Czech Science Foundation and the grant MSM 6198959216 from the Ministry of Education, Youth and Sports.

\section{REFERENCES}

1. Morazzoni P, Bombardelli E. (1995) Silybum marianum (Carduus marianus). Fitoterapia 64, 3-42.

2. Šimánek V, Křen V, Ulrichová J, Vičar J, Cvak L. (2000) Silymarin: What is in the name? Hepatology 32, 442-443.

3. Szilági I, Téténzi P, Antus S, Selingmann O, Chari VM, Seitz M, Wagner H. (1981) Structure of silandrin and silymonin. 2. New flavonolignans from a white blooming Silybum marianum variety. Planta Med 43, 121-127.

4. Flora K, Hahn M, Rosen H, Benner K. (1998) Milk thistle (Silybum marianum) for the therapy of liver disease. Am J Gastroenterol 93, 139-143.

5. de Groot H, Rauen M. (1998) Tissue injury by reactive oxygen species and the protective effects of flavonoids. Fundam Clin Pharmacol 12, 249-255.

6. Blumenthal M, Busse W. (1998) The complete german commission E monographs: Therapeutic guide to herbal medicines. American botanical council and integrative medicine communications, Austin, TX 1998, pp. 685-698.

7. Fraschini F, Dermartini G, Esposti D. (2002) Pharmacology of silymarin. Clin Drug Invest 22, 51-65.

8. Mulrow C, Lawrence V, Jacobs B. (2000) Milk thistle: Effects on liver disease and cirrhosis and clinical adverse effects. Evidence Report/Technology Assessment No. 21 (Contract 290-97-0012, AHRQ Publication No. 01-E025. Rockville, MD: Agency for Healthcare Research and Quality. http://www.ahrq.gov/clinic/epcsums/milktsum.htm.

9. Saller R, Meier R, Brignoli R. (2001) The use of silymarin in the treatment of liver diseases. Drugs 61, 2035-2063.

10. Jacobs BP, Dennehy C, Ramirez G, Sapp J, Lawrence VA. (2002) Milk thistle for the treatment of liver disease: A systematic review and meta-analysis. Am J Med 113, 506-515.

11. Anonymous. (1999) Adverse drug reactions advisory committee. An adverse reaction to the herbal medication milk thistle (Silybum marianum). Med J Aust 170, 218-219.

12. Geier J, Fuchs TH, Wahl R. (1990) Anaphylactic shock due to an extract of Silybum marianum in a patient with immediate-type allergy to kiwi fruit. Allergologie 13, 387-388.
13. Mironets VI, Krasovskayia EA. (1990) A case of urticaria during carsil treatment. Vrach Delo 7, 86-87.

14. Vinh PQ, Sugie S, Tanaka T, Hara A, Yamada Y, Katayama M, Deguchi T, Mori H. (2002) Chemopreventive effects of a flavonoid antioxidant silymarin on $N$-butyl- $N$-(4-hydroxybutyl)nitrosamineinduced urinary bladder carcinogenesis in male ICR mice. Jpn $\mathrm{J}$ Cancer Res 93, 42-49.

15. Kohno H, Tanaka T, Kawabata K, Hirose I, Sugie S, Tsuda H, Mori H. (2002) Silymarin, a naturally occurring polyphenolic antioxidant flavonoid, inhibits azoxymethane-induced colon carcinogenesis in male F344 rats. Int J Cancer 101, 461-468.

16. Lahiri-Chatterjee M, Katiyar SK, Mohan RR, Agarwal R. (1999) A flavonoid antioxidant silymarin affords exceptionally high protection against tumor promotion in the SENCAR mouse skin tumorigenesis model. Cancer Res 59, 622-632.

17. Agarwal R, Katiyar SK, Lundgren DW, Mukhtar H. (1994) Inhibitory effect of silymarin, an anti-hepatotoxic flavonoid, on 12-O-tetradecanoylphorbol-13-acetate-induced epidermal ornitine decarboxylase activity and mRNA in SENCAR mice. Carcinogenesis $15,1099-1103$.

18. Zhao J, Sharma Y, Agarwal RA. (1999) Flavonoid antioxidant, silymarin, affords significant inhibition against 12-O-tetradecanoylphorbol 13-acetate-caused modulation of antioxidant and inflammatory enzymes, and cyclooxygenase 2 and interleukin-1a expression in SENCAR mouse epidermis: implications in the prevention of stage I tumor. Mol Carcinog 26, 321-333.

19. Zhao J, Lahiri-Chatterjee M, Sharma Y, Agarwal R. (2000) Inhibitory effect of a flavonoid antioxidant silymarin on benzoyl peroxide-induced tumor promotion, oxidative stress and inflamatory responses in SENCAR mouse skin. Carcinogenesis 21, 811-816.

20. Dorai T, Aggarwal BB. (2004) Role of chemopreventive agants in cancer therapy. Cancer Lett 215, 129-140.

21. Ahmad N, Gali H, Javed S, Agarwal R. (1998) Skin cancer chemoprotective effects of a flavonoid antioxidant silymarin are mediated via impairment of receptor tyrosine kinase signaling and perturbation in cell cycle progression. Biochem Biophys Res Commun 248, 294-301.

22. Zi X, Mukhtar H, Agarwal R. (1997) Novel cancer chemopreventive effects of a flavonoid antioxidant silymarin: Inhibition of mRNA expression of an endogenous tumour promoter TNF $\alpha$. Biochem Biophys Res Commun 239, 334-339.

23. Zi X, Feyes DK, Agarwal R. (1998) Anticarcinogenic effect of a flavonoid antioxidant, silymarin, in a human breast cancer cells MDAMB 468: Induction of G1 arrest through an increase in Cip1/p21 concomitant with a decrease in kinase activity of cyclin-dependent kinases and associated cyclins. Clin Cancer Res 4, 1055-1064.

24. Zi X, Agarwal R. (1999) Modulation of mitogen-activated protein kinase activation and cell cycle regulators by the potent skin cancer preventive agent silymarin. Biochem Biophys Res Commun 263, 528-536.

25. Singh RP, Tyangi AK, Zhao J, Agarwal R. (2002) Silymarin inhibits growth and causes regression of established skin tumors in SENCAR mice via modulation of mitogen-activated protein kinases and induction of apoptosis. Carcinogenesis 23, 499-510.

26. Singh RP, Agarwal R. (2002) Flavonoid antioxidant silymarin and skin cancer. Antioxid Redox Signal 4, 655-663.

27. Kang SN, Lee MH, Kim K-M, Cho D, Kim TS. (2001) Induction of human promyelocytic leukemia HL-60 cell differentiation into monocytes by silibinin: involvement of protein kinase $\mathrm{C}$. Biochem Pharmacol 61, 1487-1495.

28. Zi X, Agarwal R. (1999) Silibinin decreases prostate-specific antigen with cell growth inhibition via G1 arrest, leading to differentiation of prostate carcinoma cells: implications for prostate cancer intervention. Proc Natl Acad Sci USA 96, 7490-7495.

29. Bhatia N, Agarwal R. (2001) Detrimental effect of cancer preventive phytochemicals silymarin, genistenin and epigallocatechin 3galate on epigenetic events in human prostate carcinoma DU145 cells. The Prostate 46, 98-107.

30. Zi X, Zhang J, Agarwal R, Pollak M. (2000) Silibinin up-regulates insulin-like growth factor-binding protein 3 expression and inhibits proliferation of androgen-independent prostate cancer cells. Cancer Res 60, 5617-5620. 
31. Zhu W, Zhang J-S, Young YF. (2001) Silymarin inhibits function of the androgen receptor by reducing nuclear localization of the receptor in the human prostate cancer cell line LNCaP. Carcinogenesis 22, 1399-1403.

32. Thelen P, Jarry H, Ringert R-H, Wuttke W. (2004) Silibinin downregulates prostate epithelium-derived Ets transcription factor in LNCaP prostate cancer cells. Planta Med 70, 397-400.

33. Jiang C, Agarwal R, Lu JX. (2000) Anti-angiogenic potential of a cancer chemopreventive flavonoid antioxidant, silymarin: Inhibition of key attributes of vascular endotelial cells and angiogenic cytokine secretion by cancer epitelial cells. Biochem Biophys Res Commun 276, 371-378.

34. Gallo D, Giacomelli S, Ferlini C, Raspaglio G, Apollonio P, Prisley S, Riva A, Morazzoni P, Bombardelli E, Scambia G. (2003) Antitumour activity of the silybin-phosphatidylcholine complex IdB 1016, against human ovarian cancer. Eur J Cancer 39, 2403-2410.

35. Ladas EJ, Kelly KM. (2003) Milk thistle: Is there a role for its use as an adjunct therapy in patients with cancer? J. Alternative and Complementary Med. 9, 411-416.

36. Invernizzi R, Bernuzzi S, Ciani D, Ascari E. (1993) Silymarin during maintenance therapy of acute promyelocytic leukemia. Haematologica 78, 340-341.

37. Scambia G, De Vincenzo R, Ranelletti FO, Panici PB, Ferrandina G, D’Agostino G, Fattorossi A, Bombardelli E, Mancuso S. (1996) Antiproliferative effect of silybin on gynecological malignancies: Synergism with cisplatin and doxorubicin. Eur J Cancer $32 A$, $877-882$.

38. Giacomelli S, Gallo D, Apollonio P, Ferlini C, Distefano M, Morazzoni P, Riva A, Bombardelli E, Mancuso S, Scambia G. (2002) Silybin and its bioavailable complex (IdB 1016) potentiate in vitro and in vivo the activity of cisplatin. Life Sci 70, 1447-1459.

39. Bokemeyer C, Fels LM, Dunn T, Voigt W, Gaedeke J, Schmoll H-J, Stolte H, Lentzen H. (1996) Silibinin protects against cisplatin-induced nephrotoxicity without compromising cisplatin or ifosfamide anti-tumour activity. Br J Cancer 74, 2036-2041.

40. Kuhlmann MK, Horsch E, Burkhardt G, Wagner M, Kohler H. (1998) Reduction of cisplatin toxicity in cultured renal tubular cells by the bioflavonoid quercetin. Arch Toxicol 72, 536-540.

41. Tyagi AK, Agarwal C, Chan DCF, Agarwal R. (2003) Synergistic anti-cancer effects of silibinin with conventional cytotoxic agents doxorubicin, cisplatin and carboplatin against human breast carcinoma MCF-7 and MDA-MB468 cells. Oncol Rep 11, 493-499.

42. Piscitelli SC, Formentini E, Burstein AH, Alfaro R, Jagannatha S, Falloon J. (2002) Effect of milk thistle on the pharmacokinetics of indinavir in healthy volunteers. Pharmacotherapy 22, 551-556.

43. DiCenzo R, Shelton M, Jordan K, Koval C, Forrest A, Reichman R, Morse G. (2003) Coadministration of milk thistle and indinavir in healthy subjects. Pharmacotherapy 23, 866-870.

44. Soose M. (1994) Properties of silybin and of antioxidants against adriamycin cytotoxicity in a unicellular eukaryote Tetrahymena thermophila. Eur J Protistol 30, 394-403.

45. Wang MJ, Lin WW, Chen HL, Chang YH, Ou HC, Kuo JS, Hong JS, Jeng KCG. (2002) Silymarin protects dopaminergic neurons against lipopolysaccharide-induced neurotoxicity by inhibiting microglia activation. Eur J Neurosci 16, 2103-2112.

46. Kittur S, Wilasrusmee S, Pedersen WA, Mattson MP, Straube-West K, Wilasrusmee C, Jubelt B, Kittur DS. (2002) Neurotrophic and neuroprotective effects of milk thistle (Silybum marianum) on neurons in culture. J Molec Neurosci 18, 265-269.

47. Schroeter H, Williams RJ, Matin R, Iversen L, Rice-Evans CA. (2000) Phenolic antioxidants attenuate neuronal cell death following uptake of oxidized low-density lipoprotein. Free Radic Biol Med 29, 1222-1233.

48. La Grange L, Wang M, Watkins R, Ortiz D, Sanchez ME, Konst J, Lee C, Reyes E. (1999) Protective effects of the flavonoid mixture, silymarin, on fetal rat brain and liver. J Ethnopharmacol 65 , 53-61.

49. Mazzio E, Huber J, Darling S, Harris N, Soliman KFA. (2001) Effect of antioxidants on L-glutamate and $\mathrm{N}$-methyl-4-phenylpyridinium ion induced-neurotoxicity in PC12 cells. Neurotoxicology 22, 283-288.
50. Sakai K, Li Y, Shirakawa T, Kitagawa Y, Hirose G. (2001) Induction of major histocompatibility complex class I molecules on human neuroblastoma line cells by a flavonoid antioxidant. Neurosci Lett 298, 127-130.

51. Soto C, Perez BL, Favari LP, Reyes JL. (1998) Prevention of alloxan-induced diabetes mellitus in the rat by silymarin. Comp Biochem Physiol C 119, 125-129.

52. Soto C, Recoba R, Barron H, Alvarez C, Favari L. (2003) Silymarin increases antioxidant enzymes in alloxan-induced diabetes in rat pancreas. Comp Biochem Physiol C 136, 205-212.

53. Soto C, Mena R, Luna J, Cerbon M, Larrieta E, Vital P, Uria E, Sanchez M, Recoba R, Barron H, Favari L, Larag A. (2004) Silymarin induces recovery of pancreatic function after alloxan damage in rats. Life Sci 75, 2167-2180.

54. Matsuda T, Ferreri K, Todorov I, Kuroda Y, Smith CV, Kandeel F, Mullen Y. (2005) Silymarin protects pancreatic $\beta$-cells against cytokine-mediated toxicity: Implication of c-Jun $\mathrm{NH}_{2}$-terminal kinase and Janus kinase/signal transducer and activator of transcription pathways. Endocrinology 146, 175-185.

55. Kang JS, Jeon YJ, Park SK, Yang KH, Kim HM. (2004) Protection against lipopolysaccharide-induced sepsis and inhibition of interleukin-1 $\beta$ and prostaglandin E2 synthesis by silymarin. Biochem Pharmacol 67, 175-181.

56. Cho JY, Kim PS, Park J, Yoo ES, Baik KU, Kim YK, Park MH. (2000) Inhibitor of tumor necrosis factor- $\alpha$ production in lipopolysaccharide-stimulated RAW264.7 cells from Amorpha fruticosa. J Ethnopharmacol 70, 127-133.

57. von Schönfeld J, Weisbrod B, Müller MK. (1997) Silibinin, a plant extract with antioxidant and membrane stabilizing properties, protects exocrine pancreas from cyclosporin A toxicity. Cell Mol Life Sci 53, 917-920.

58. Maghrani M, Zeggwagh NA, Lemhadri A, El Amraoui M, Michel JB, Eddouks M. (2004) Study of the hypoglycaemic activity of Fraxinus excelsior and Silybum marianum in an animal model of type 1 diabetes mellitus. J Ethnopharmacol 91, 309-316.

59. Cruz T, Gálvez J, Crespo E, Ocete MA, Zarzuelo A. (2001) Effects of silymarin on the acute stage of the trinitrobenzenesulphonic acid model of rat colitis. Planta Med 67, 94-96.

60. Kim D-H, Jin Y-H, Park J-B, Kobashi K. (1994) Silymarin and its components are inhibitors of $\beta$-glucuronidase. Biol Pharm Bull 17, 443-445.

61. Yang SH, Lin JK, Chen WS, Chiu JH. (2003) Anti-angiogenic effect of silymarin on colon cancer LoVo cell line. J Surgical Res $113,133-138$.

62. Agarwal C, Singh RP, Dhanalakshmi S, Tyagi AK, Tecklenburg M, Sclafani RA, Agarwal R. (2003) Silibinin upregulates the expression of cyclin-dependent kinase inhibitors and causes cell cycle arrest and apoptosis in human colon carcinoma HT-29 cells. Oncogene 22, 8271-8282.

63. Ahlenstiel T, Burkhardt G, Köhler H, Kuhlmann MK. (2003) Bioflavonoids attenuate renal proximal tubular cell injury during cold preservation in Euro-Collins and University of Wisconsin solutions. Kidney Int 63, 554-563.

64. Sonnenbichler J, Scalera F, Sonnenbichler I, Weyhenmeyer R. (1999) Stimulatory effects of silibinin and silicristin from the milk thistle Silybum marianum on kidney cells. J Pharm Exp Ther 290, 1375-1383.

65. Rastogi R, Srivastava AK, Rastogi AK. (2001) Long term effect of aflatoxin B1 on lipid peroxidation in rat liver and kidney: Effect of picroliv and silymarin. Phytother Res 15, 307-310.

66. He QR, Kim J, Sharma RP. (2002) Silymarin protects against liver damage in BALB/c mice exposed to fumonisin B-1 despite increasing accumulation of free sphingoid bases. Toxicol Sci 90 , 268-277.

67. Dietzmann J, Thiel U, Ansorge S, Neumann KH, Tager M. (2002) Thiol-inducing and immunoregulatory effects of flavonoids in peripheral blood mononuclear cells from patients with end-stage diabetic nephropathy. Free Radical Biol Med 33, 1347-1354.

68. Vereckei AS, Blázovics A, György I, Fehér E, Tóth M, Szénási G, Zsinka ÁJN, Földiák G, Fehér J. (1993) The role of free radicals in the pathogenesis of amiodarone toxicity. J Cardiovasc Electrophysiol 4, 161-177. 
69. Vereckei AS, Besch HR, Zipes DP. (2003) Combined amiodarone and silymarin treatment, but not amiodarone alone, prevents sustained atrial flutter in dogs. J. Cardiovasc Electrophysiol 14, 861-867.

70. Ágoston M, Örsi F, Feher E, Hagymási K, Orosz Z, Blázovics A, Fehér J, Vereckei A. (2003) Silymarin and vitamin E reduce amiodarone-induced lysosomal phospholipidosis in rats. Toxicology 190, 231-241.

71. Ágoston M, Cabello R-G, Blázovics A, Fehér J, Vereckei A. (2001) The effect of amiodarone and/or antioxidant treatment on splenocyte blast transformation. Clin Chim Acta 303, 87-94.

72. Gyonos I, Ágoston M, Kovacs A, Szénási G, Vereckei A. (2001) Silymarin and vitamin E do not attenuate and vitamin E might even enhance the antiarrhytmic activity of amidarone in a rat reperfusion arrhytmia model. Cardiovasc Drugs Ther 15, 233-235.

73. Chlopčíková A, Psotová J, Miketová P, Šimánek V. (2004) Chemoprotective effect of plant phenolics against anthracycline-induced toxicity on rat cardiomyocytes. Part I. Silymarin and its flavonolignans. Phytoterapy Res 18, 107-110.

74. Psotová J, Chlopčíková S, Grambal F, Šimánek V, Ulrichová J. (2002) Influence of silymarin and its flavonolignans on doxorubicin-iron induced lipid peroxidation in rat heart microsomes and mitochondria in comparison with quercetin. Phytother Res 16, S63-S67.

75. Singh RP, Mallikarjuna GU, Sharma G, Dhanalakshmi S, Tyagi AK, Chan DCF, Agarwal C, Agarwal R. (2004) Oral silibinin inhibits lung tumor growth in athymic nude mice and forms a novel chemocombination with doxorubicin targeting nuclear factor $\kappa \mathrm{B}$-mediated inducible chemoresistance. Clin Canc Res 10, 8641-8647.

76. Chu SC, Chiu HL, Chen PN, Yang SF, Hsieh YS. (2004) Silibinin inhibits the invasion of human lung cancer cells via decreased productions of urokinase-plasminogen activator and matrix metalloproteinase-2. Molec Carcinogen 40, 143-149.

77. Breschi MC, Martinotti E, Apostoliti F, Nieri P. (2002) Protective effect of silymarin in antigen challenge- and histamine-induced bronchoconstriction in in vivo guinea-pigs. Eur J Pharmacol 437, 91-95.

78. Katiar SK. (2005) Silymarin and skin cancer prevention: Antiinflammatory, antioxidant and immunomodulatory effects. Int $\mathbf{J}$ Oncol 26, 169-176.

79. Afaq F, Adhami VM, Ahmad N, Mukhtar H. (2002) Botanical antioxidants for chemoprevention of photocarcinogenesis. Front Biosci 7, 784-92.

80. Katiyar SK, Korman NJ, Mukhtar H, Agarwal R. (1997) Protective effects of silymarin against photocarcinogenesis in a mouse skin model. J Natl Cancer Inst 89, 556-66.

81. Mallikarjuna G, Dhanalakshmi S, Singh RP, Agarwal C, Agarwal R. (2004) Silibinin protects against photocarcinogenesis via modulation of cell cycle regulators, mitogen-activated protein kinases, and Akt signaling. Cancer Res 64, 6349-6356.

82. Svobodová A, Psotová J, Walterová D. (2005) Flavonolignans prevent UVA-induced cytotoxicity in human keratinocytes. J Photochem Photobiol - submitted

83. Katiyar SK. (2002) Treatment of silymarin, a plant flavonoid, prevents ultraviolet light-induced immune suppression and oxidative stress in mouse skin. Int J Oncol 21, 1213-1222.

84. Lahiri-Chatterjee M, Agarwal R, Mukhtar H. (1996) Ultraviolet B radiation-induced DNA lesions in mouse epidermis: An assessment using a novel ${ }^{32} \mathrm{P}$-postlabelling technique. Biochem Biophys Res Commun 229, 590-595.

85. Mohan S, Dhanalakshmi S, Mallikarjuna GU, Singh RP, Agarwal R. (2004) Silibinin modulates UVB-induced apoptosis via mitochondrial proteins, caspases activation, and mitogen-activated protein kinase signaling in human epidermoid carcinoma A431 cells Biochem Biophys Res Commun 320, 183-189.

86. Dhanalakshmi S, Mallikarjuna GU, Singh RP, Agarwal R. (2004) Dual efficacy of silibinin in protecting or enhancing ultraviolet B radiation-caused apoptosis in $\mathrm{HaCaT}$ human immortalized keratinocytes. Carcinogenesis 25, 99-106.

87. Goodin MG, Fertuck KC, Zacharewski TR, Rosengren RJ. (2002) Estrogen receptor-mediated actions of polyphenolic catechins in vivo and in vitro. Toxicol Sci 69, 354-361.
88. Han D-H, Denison MS, Tachibana H, Yamada K. (2002) Relationship between estrogen receptor-binding and estrogenic activities of environmental estrogens and suppression by flavonoids. Biosci Biotechnol Biochem 66, 1479-1487.

89. Mueller SO, Simon S, Chae K, Metzler M, Korach KS. (2004) Phytoestrogens and their human metabolites show distinct agonistic and antagonistic properties on estrogen receptor $\alpha(\operatorname{ER} \alpha)$ and ER $\beta$ in human cells. Toxicol Sci 80, 14-25.

90. Seidlová-Wuttke D, Becker T, Christoffel V, Jarry H, Wuttke W. (2003) Silymarin is a selective estrogen receptor $\beta$ (ER $\beta)$ agonist and has estrogenic effects in the metaphysis of the femur but no or antiestrogenic effects in uterus of ovariectomized (ovx) rats. J Steroid Biochem Mol Biol 86, 179-188.

91. Kummer V, Mašková J, Čanderle J, Zralý Z, Neča J, Machala M. (2001) Estrogenic effects of silymarin in ovariectomized rats. Vet Med-Czech 46, 17-23.

92. Plišková M, Vondráček J, Křen V, Gažák R, Sedmera P, Walterová D, Psotová J, Šimánek V, Machala M. (2005) Effects of silymarin flavonolignans and synthetic silybin derivatives on estrogen and aryl hydrocarbon receptor activation. Toxicology - in press

93. Zhou SF, Lim LY, Chowbay B. (2004) Herbal modulation of P-glycoprotein. Drug Metab Rev 36, 1-48.

94. Zhang SH, Morris ME. (2003) Effects of the flavonoids biochanin A, morin, phloretin, and silymarin on P-glycoprotein-mediated transport. J Pharm Exp Ther 304, 1258-1267.

95. Tyagi AK, Singh RP, Agarwal C, Chan DC, Agarwal R. (2002) Silibinin strongly synergizes human prostate carcinoma DU145 cells to doxorubicin-induced growth inhibition, G2-M arrest, and apoptosis. Clin Cancer Res 8, 3512-3519.

96. Maitrejean M, Comte G, Barron D, El Kirat K, Gwenaelle C, Di Pietro A. (2000) The flavanolignan silybin and its hemisynthetic derivatives, a novel series of potential modulators of P-glycoprotein. Bioorg Med Chem Lett 10, 157-160.

97. Džubák P, Hajduch M, Gažák R, Walterová D, Svobodová A, Psotová J, Sedmera P, Křen V. (2005) New derivatives of silybin and 2,3-dehydrosilybin and their cytotoxic and P-glycoprotein modulatory activity. Bioorg Med Chem - submitted

98. Beckmann-Knopp S, Rietbrock S, Weyhenmeyer R, Bocker RH, Beckurts KT, Lang W, Hunz M, Fuhr U. (2000) Inhibitory effects of silibinin on cytochrome P-450 enzymes in human liver microsomes. Pharmacol Toxicol 86, 250-256.

99. Pérez-Victoria JM, Pérez-Victoria FJ, Conseil G, Maitrejean M, Comte G, Barron D, DiPietro A, Castanys S, Gamarro F. (2001) High-affinity binding of silybin derivatives to the nucleotide-binding domain of a Leishmania tropica P-glycoprotein-like transporter and chemosenzitization of a multidrug-resistant parasite to daunomycin. Antimicrob Agents Chemother 45, 439-446.

100. Nguyen H, Zhang SZ, Morris ME. (2002) Effect of flavonoids on MRP1-mediated transport in Panc-1 cells. J Pharm Sci 92, 250-257.

101. Leslie EM, Mao Q, Oleschuk CJ, Deeley RG, Cole SPC. (2001) Modulation of multidrug resistance protein 1 (MRP1/ABCC1) transport and ATPase activities by interaction with dietary flavonoids. Molecular Pharmacol 59, 171-1180.

102. Stermitz FR, Tawara-Matsuda J, Lorenz P, Mueller P, Zenewicz L, Lewis K. (2000) 5'-Methoxyhydnocarpin-D and pheophorbide A: Berberis species components that potentiate berberine growth inhibition of resistant Staphylococcus aureus. J Nat Prod 63, 1146-1149.

103. Stermitz FR, Beeson TD, Mueller PJ, Hsiang J-F, Lewis K. (2001) Staphylococcus aureus MDR efflux pump inhibitors from a Berberis and a Mahonia (sensu stricto) species. Biochem System Ecol 29, 793-798.

104. Guz NR, Starmitz FR, Johnson JB, Beson TD, Willen S, Hsiang J-F, Lewis K. (2001) Flavonolignan and flavone inhibitors of a Staphylococcus aureus multidrug resistance pump: Structure-activity relationships. J Med Chem 44, 261-268.

105. Mäser P, Vogel D, Schmid C, Räz B, Kaminski R. (2001) Identification and characterization of trypanocides by functional expression of an adenosine transporter from Trypanosoma brucei in yeast. J Mol Med 79, 121-127. 
106. Saliou C, Rihn B, Cillard J, Okamoto T, Packer L. (1998) Selective inhibition of NF- $\kappa \mathrm{B}$ activation by the flavonoid hepatoprotector silymarin in HepG2. FEBS Lett 440, 8-12.

107. Saliou C, Valacchi G, Rimbach G. (2001) Assessing bioflavonoids as regulators of NF- $\kappa \mathrm{B}$ activity and inflammatory gene expression in mammalian cells. Meth Enz 335, 380-386.

108. Manna SK, Mukhopadhyay A, Van NT, Aggarwal BB. (1999) Silymarin suppresses TNF-induced activation of NF-кB, c-Jun N-terminal kinase, and apoptosis. J Immunol 163, 6800-6809.

109. Yoo HG, Jung SN, Hwang YS, Park JS, Kim MH, Jeong M, Ahn SJ, Ahn BW, Shin BA, Park RK, Jung YD. (2004) Involvement of $\mathrm{NF}-\kappa \mathrm{B}$ and caspases in silibinin-induced apoptosis of endothelial cells. Int J Molec Med 13, 81-86.

110. Dhanalakshmi S, Singh RP, Agarwal C, Agarwal R. (2002) Silibinin inhibits constitutive and TNF alpha-induced activation of NF-alpha B and sensitizes human prostate carcinoma DU145 cells to TNF alpha-induced apoptosis. Oncogene 21, 1759-1767.

111. Kang JS, Park SK, Yang KH, Kim HM. (2002) Silymarin inhibits TNF- $\alpha$-induced expression of adhesion molecules in human umbilical vein endothelial cells. FEBS Lett 550, 89-93.

112. Ding T-M, Tian S-J, Zhang Z-X, Gu D-Z, Chen Y-F, Shi Y-H, Sun Z-P. (2001) Determination of active component in silymarin by RP-LC and LC/MS. J Pharm Biomed Anal 26, 155-161.

113. Křen V, Sedmera P, Kubisch J, Halada P, Přikrylová V, Jegorov A, Cvak L, Gebhardt R, Ulrichová J, Šimánek V. (1997) Glycosylation of silybin. J Chem Soc, Perkin 1 1997, 2467-2474.

114. Lee DYW, Liu YZ. (2003) Molecular structure and stereochemistry of silybin A, silybin B, isosilybin A, and isosilybin B, isolated from Silybum marianum (Milk thistle). J Nat Prod 66, 1171-1174.

115. Kim NC, Graf TN, Sparacino CM, Wani MC, Wall ME. (2003) Complete isolation and characterization of silybins and isosilybins from milk thistle (Silybum marianum). Org Biomol Chem 1, 1684 1689.

116. Weyhenmeyer R, Mascher H, Birkmayer J. (1992) Study on dose-linearity of the pharmacokinetics of silibinin diastereomers using a new stereospecific assay. Int J Clin Pharmacol Ther Toxicol 30 134-138.

117. Křen V, Ulrichová J, Kosina P, Stevenson D, Sedmera P, Přikrylová V, Halada P, Šimánek V. (2000) Chemoenzymatic preparation of silybine $\beta$-glucuronide and their biological evaluation. Drug Metabolism and Disposition 28, 1513-1517.
118. Braatz R, Gurler K, Bergish G, Halbach G, Soicke H, Schmidt K. (1985) Czech. Patent 273610, 1985; Chem. Abstr. 1985, 105, P127476b).

119. Kubisch J, Sedmera P, Halada P, Gažák R, Škottová N, Šimánek V, Křen V. (2001) Chemoenzymatic preparation of oligoglycosides of silybin, the flavonolignan from Silybum marianum. Heterocycles 53, 901-915.

120. Škottová N, Švagera Z, Večeřa R, Urbánek K, Jegorov A, Šimánek V. (2001) Pharmacokinetic study of iodine-labeled silibinins in rat. Pharm Res 44, 247-253.

121. Gažák R, Svobodová A, Psotová J, Sedmera P, Přikrylová V, Walterová D, Křen V. (2004) Oxidised derivatives of silybin and their antiradical and antioxidant activity. Bioorg Med Chem 12, 5677-5687.

122. Rodriguez RJ, Miranda CL, Stevens JF, Deinzer ML, Buhler DR. (2001) Influence of prenylated and non-prenylated flavonoids on liver microsomal lipid peroxidation and oxidative injury in rat hepatocytes. Food Chem Toxicol 39, 437-445.

123. Křen V, Minghetti A, Sedmera P, Havlíček V, Přikrylová V, Crespi-Perellino N. (1998) Glucosylation of silybin by plant cell cultures of Papaver somniferum var. setigerum. Phytochemistry 47, 217-220.

124. Kosina P, Křen V, Gebhardt R, Grambal F, Ulrichová J, Walterová D. (2001) Antioxidant properties of silybin glycosides. Phytother Res 15, 1-7.

125. Šimánek V, Walterová D, Vičar J, Urbaníková J, Křen V, Modrianský M, Škottová N, Ulrichová J. (2001) "Silymarin”, extract from the milk thistle (Silybum marianum) - medicine or a nutraceutics? Česká a Slovenská Farmacie 50, 66-69.

126. Zhang SZ, Morris ME. (2003) Effect of the flavonoids biochanin A and silymarin on the P-glycoprotein-mediated transport of digoxin and vinblastine in human intestinal Caco-2 cells. Pharm Res 20, 1184-1191

127. Zuber R, Modrianský M, Dvořák Z, Rohovský P, Ulrichová J, Šmánek V, Anzenbacher P. (2002) Effect of silybin and its congeners on human liver microsomal cytochrome $\mathrm{P} 450$ activities. Phytother Res 16, 632-638.

128. Kosina P, Maurel P, Ulrichová J, Dvořák Z. (2005) Effect of silybin and its glycosides on the expression of cytochromes P450 1A2 and 3A4 in primary cultures of human hepatocytes. J Biochem Mol Toxicol 19, 149-153.

129. Svobodová A, Psotová J, Walterová D. (2004) Natural phenolics in the prevention of UV-induced skin damage. Biomed Papers 147 , $137-145$. 